\title{
Amputee sexual dysfunction
}

Volume 4 Issue 4 - 2016

\author{
Anthony E Johnson, MAJ Jessica C Rivera \\ Department of Orthopaedic Surgery, San Antonio Military \\ Medical Center, USA
}

\section{Editorial}

Recent combat operations in Iraq and Afghanistan have resulted in over 1,200 patients with major limb amputations, more than $75 \%$ of whom have amputations of the lower extremity. ${ }^{1}$ Outcomes of limb amputation from the trauma and orthopaedic perspectives have been extensively studied in the military and civilian trauma literature. However, it was not until the Lower Extremity Assessment Project (LEAP) Study Group published how personal perceptions, such as self-efficacy, can positively or adversely affect outcomes that the orthopaedic trauma community began to appreciate the role that one's own image of self plays in recovery and reintegration. ${ }^{2}$ Along these lines, health care providers should be sensitive to the multiplicity of influences affecting patients' self-image, quality of life, and thus, optimal rehabilitation.

Among these influences are one's sexual and reproductive health. The Iraq and Afghanistan generation of war veterans with amputations may find that their amputations impact their sexuality and vice versa.

Aberrations in sexual health within the military culture is documented even in uninjured service members. The military culture emphasizes fitness, endurance, performance, and resilience. These masculine "values" likely reflect the male predominance in the military but also overlap with an emphasis on an ideal, vigorous, capable body, ${ }^{3}$ placing a service member with any perceived body image deficiency at risk of sexual dysfunction. A recent survey of male military personnel without bodily injury found erectile dysfunction rates as high as $33 \%{ }^{4}$

Adding common military related comorbidities, such as Post Traumatic Stress Disorder (PTSD), raises this rate to nearly $80 \%{ }^{5}$ The military culture is not entirely perceived differently by females as a strong, independent body is likewise valued by service women. As with men, women veterans with no bodily injury are more likely than their civilian counterparts to have sexual health or reproductive complaint; and this is likewise compounded in the face of mental health diagnoses (such as PTSD) and for women with a history of sexual trauma sustained while in the military. ${ }^{6,7}$

Beyond what appears to be a baseline risk of body image influenced sexual dysfunction, a service member who sustains an amputation is likely to experience compounded effects due to the effect of the amputation on body image and his or her experience as a "whole" person. The literature suggests that $20 \%$ of persons with amputation experience some sexual dysfunction. ${ }^{8}$ Over $40 \%$ of persons with amputation experience a change in their sex life compared to before their amputation. ${ }^{9}$ Female amputees report a heightened sense of anxiety and avoidance of intimacy after their amputations. ${ }^{10}$ However, amputees report little to no discussion about sexual health from health care providers during rehabilitation. ${ }^{8}$

Studies on sexuality and the military amputee specifically are sparse. One phenomenological study found that female combat amputees do perceive their bodies differently than male amputees, even in the absence of sexual dysfunction, reporting being heavy influenced by the social perceptions of a feminine body and concerns for personal safety due to their injury. ${ }^{11}$ Otherwise, sexual dysfunction is beginning to receive due attention following injury patterns associated with genitourinary trauma, such as dismounted complex blast injury which results in a constellation of peroneal trauma and lower extremity amputation. ${ }^{12,13}$ Sexual rehabilitation from a relationship and intimacy perspective, even in the setting of peroneal trauma however, has not been emphasized. ${ }^{14,15}$

While a hyper-masculine military culture as a whole may contribute to the body image and sexual struggles faced by an injured service member, there exists a subculture of Wounded. Warriors which may be leveraged to benefit combat amputees. The author's personnel experience with greater than eight years caring for wounded service members within San Antonio Military Medical Center's Department of Orthopaedics and Rehabilitation suggests that wounded service members form a very tightly knit community where the shared experience of war and combat injury strengthens and fortifies itself. This is highly evident within the amputee culture where members self-engage in peer mentoring through rehabilitation course and prosthetic fitting and troubleshooting. A majority of amputee physical rehabilitation during recent wars has been conducted at major amputation centers where peer and social support are ingrained into the health care culture. Only within the past year has a Sexual Health and Intimacy Clinic been opened at Walter Reed National Medical Center due to funding support from the Bob Woodruff Foundation and SemperMax Support Fund. This effort was designed to reinforce the social aspect of healing and the repair home relationships through intimacy.

To summarize, military culture promotes a specific valued body image which can predispose military personnel to psychological aspects of sexual dysfunction. Injury, including amputations, which also dramatically alter one's body image, may compound this, especially in light of a lack of sexual rehabilitation. Wounded Warriors 
including combat amputees within their own culture are highly supportive of each other and may provide the best grounds on which to build rehabilitation efforts towards sexual health and intimacy. As such, health care providers who care for veterans with amputations must be cognizant of how a patient's body image could affect his or her participation in physical and mental health rehabilitation and identify how sexual health contributes to social reintegration and maintenance of home relationships ${ }^{17}$ Even in the absence of specialty sexual health clinics, validated screening tools are widely available to help providers identify patients with sexual health concerns. Finally, health care providers must also recognize that once a patient leaves the supportive environment of a dedicated amputee rehabilitation setting, he or she has then lost both the eliteness found in the military culture and the unity found in the Wounded Warrior culture. Care at this stage may require an even greater emphasis on psychological health, social wellbeing, and confidence in reintegration, all of which may influence and may be influenced by sexual health. ${ }^{14}$

\section{Acknowledgments}

None.

\section{Conflicts of interest}

None.

\section{References}

1. Krueger CA, Wenke JC, Ficke JR. Ten years at way: comprehensive analysis of amputation trends. J Trauma Acute Care Surg. 2012;73(6 Suppl 5):S438-S444.

2. Bosse MJ1, MacKenzie EJ, Kellam JF, et al. An analysis of outcomes of reconstruction of amputation of leg-threatening injuries. $N$ Engl J Med. 2002;347(24):1924-1931

3. Weber JP, Rosen LN, Weissbrod C. Gender-based personality traits and military cohesion. Mil . 2000;165(4):297.

4. Wilcox SL, Redmond S, Davis TL. Genital image, sexual anxiety, and erectile dysfunction among young male military personnel. J Sex Med. 2005;12(6):1389-1397.

5. Wilcox SL, Redmond S, Hassan AM. Sexual functioning in military personnel: preliminary estimates and predictors. $J$ Sex Med. 2014;11(10):2537-2545.
6. Cohen BE, Maguen S, Bertenthal D, et al. Reproductive and other health outcomes in Iraq and Afghanistan women veterans using VA health care: association with mental health diagnoses. Womens Health Issues. 2012;22(5):461-471.

7. Hoge CW, Auchterlonie JL, Milliken CS. Mental health problems, use of mental health services, and attrition from military service after returning from deployment to Iraq or Afghanistan. JAMA . 2006;295(9):1023-1032.

8. Verschuren JE, Geertzen JH, Enzlin P, et al. Sexual functioning and sexual well-being in people with limb amputation: a cross-sectional study in the Netherlands. Disabil Rehabil Jun. 2016;38(4):368-373.

9. Ide M. Sexuality in person with limb amputation: a meaningful discussion of re-integration. Disabil Rehabil. 2004;26(14-15):939-943.

10. Mathias Z, Harcourt D. Dating and intimate relationships of women with below-knee amputation: an exploratory study. Disabil Rehabil. 2014;36(5):395-402.

11. Carter JK. Traumatic amputation: psychosocial adjustment of six Army women to loss of one of more limbs. J Rebah Research Develop. 2012;49(10):1443-1456

12. Banti M, Walter J, Hudak S, et al. Improvised explosive device-related lower genitourinary trauma in current overseas combat operations. $J$ Trauma Acute Care Surg. 2016;80(1):131-134.

13. Mamczak CN, Elster EA. Complex dismounted IED blast injuries: the initial management of bilateral lower extremity amputations with and without pelvic and perineal involvement. J Surg Orthop Adv. 2012;21(1):8-14.

14. Helmer DA, Beaulieu GR, Houlette C, et al. Assessment and documentation of sexual health issues of recent combat veterans seeking VHA care. J Sex Med. 2013;10(4):1065-1073.

15. Helmer DA, Beaulieu G, Powers C, et al. Perspectives on sexual health and function of recent male combat veterans of Iraq and Afghanistan. Sex Med. 2015;3(3):137- 146.

16. Bob Woodruff Foundation High Impact Collaboration. Intimacy after injury: therapeutic advances to alleviate the devastating impact of war injury on fertility and on physical and emotional intimacy. Washington, USA. 2014.

17. Cameron RP, Mona LR, Syme ML, et al. Sexuality among wounded veterans of Operation Enduring Freedom (OEF), Operation Iraqi Freedom (OIF), and Operation New Dawn (OND): Implications for rehabilitation psychologists. Rehabil Psychol. 2011;56(4):289-301. 